\title{
ARTIGO
}

DOI: $10.22481 /$ praxis.v14i28.3474

\section{EXPECTATIVAS E CONCEPÇÃO DE ATUAÇÃO PROFISSIONAL NA PERSPECTIVA DE GRADUANDOS EM PEDAGOGIA}

\author{
EXPECTATIONS AND CONCEPTIONS OF PROFESSIONAL ACTING IN THE \\ PERSPECTIVE OF GRADUATE STUDENTS OF PEDAGOGY
}

\author{
EXPECTATIVAS Y CONCEPCIÓN DE LA ACTUACIÓN PROFESIONAL EN LA \\ PERSPECTIVA DE ESTUDIANTES EN PEDAGOGÍA
}

Carla Spagnolo

Pontifícia Universidade Católica do Rio Grande do Sul - Brasil

Jordana Wruck Timm

Universidade Regional Integrada do Alto Uruguai e das Missões - Brasil

Bettina Steren dos Santos

Pontifícia Universidade Católica do Rio Grande do Sul - Brasil

\begin{abstract}
Resumo
O presente trabalho trata de um recorte de uma investigação desenvolvida no grupo de pesquisa PROMOT, com discentes do curso de Pedagogia. Objetivou identificar as expectativas e concepções desses discentes quanto às possibilidades de atuação profissional e verificar se o currículo da instituição vai ao encontro dos mesmos. O método adotado é quanti/qualitativa, a partir da análise de uma questão aplicada a 52 estudantes ( $4^{\circ}$ ao $6^{\circ}$ semestre), sobre a concepção de atuação profissional. Os resultados encontrados apontam que $67 \%$ dos estudantes demonstraram conhecimento/expectativas em atuar no segmento Acadêmico, $30 \%$ no Corporativo e 3\% em outros segmentos.
\end{abstract}

Palavras-chave: Currículo. Expectativas discentes. Pedagogia.

\begin{abstract}
The present work deals with a research cut developed in the PROMOT research group with students of the Faculty of Education. Aimed to identify the expectations and conceptions of these students about the professional performance opportunities and verify that the curriculum of the institution meets the same. The method used is quanti/qualitative, based on the analysis of an issue applied to 52 students (4th to 6th semester), on the design of professional performance. The results show that $67 \%$ of the students demonstrated knowledge/expectations in acting in the Academic segment, 30\% in Corporate and $3 \%$ in other segments.
\end{abstract}

Keywords: Curriculum. Pedagogy. Students expectations.

\section{Resumen}

El presente trabajo trata de un recorte de un estudio desarrollado en el grupo de investigación PROMOT, con estudiantes de la Facultad de Pedagogía. Tuvo como objetivo identificar las expectativas y concepciones de estos estudiantes sobre las oportunidades de desempeño profesional y 
verificar si el plan de estudios de la institución se encuentra con el mismo. El método utilizado es cuanti/cualitativo, basado en el análisis de una cuestión aplicada a 52 estudiantes (4to a 6to semestre), en el diseño de desempeño profesional. Los resultados encontrados apuntan que $67 \%$ dos estudiantes han demostrado conocimiento/expectativas en la actuación en el segmento Académico, $30 \%$ en el Corporativo y $3 \%$ en otros segmentos.

Palabras clave: Currículum. Expectativas do los estudiantes. Pedagogía.

\section{Palavras iniciais}

Muitos acontecimentos têm desafiado o mundo e causado mudanças significativas nas diferentes áreas do conhecimento. Essa realidade requer mudanças estratégicas na tentativa de dar conta do processo de ensino e aprendizagem nas instituições de ensino. E, é nesse contexto de incertezas que, segundo Engers (2007), os educadores e as escolas/universidades têm que tomar posições e decisões.

As decisões precisam estar edificadas na construção de conceitos sobre o que é o ensinar e aprender e as suas modificações sofridas ao longo do tempo. De certa forma, é compreender que o ensino não se resume ao conteúdo livresco, a competitividade e ao domínio exclusivo do professor, nem mesmo que a aprendizagem acontece somente no ambiente de sala de aula. O momento atual exige um olhar reflexivo, questionador, aberto às incertezas e de cunho integrador entre teoria e prática.

A sociedade demanda cada vez mais profissionais capazes de gerir o conhecimento, capazes de aprender a aprender, mas também de aplicar, produzir e usar de diferentes formas o conhecimento acadêmico acumulado nas distintas áreas do saber. Por isso, torna-se fundamental questionar se o currículo da universidade atende adequadamente a essa demanda. Além disso, outras questões são relevantes: Há relação entre teoria e prática no currículo? O curso de Pedagogia atende as necessidades e expectativas dos estudantes ao mesmo tempo que segue as diretrizes nacionais?

O objetivo do estudo é analisar se o currículo de uma instituição particular de educação superior do estado do Rio Grande do Sul/Brasil atende às necessidades/expectativas dos estudantes do curso de Pedagogia para atuação profissional. Também houve a pretensão de verificar se o currículo proposto segue as diretrizes curriculares nacionais, adaptando-se de maneira flexível a realidade social e cultural, na intenção de qualificar o processo de ensino e aprendizagem e como forma de prover ações para manter os estudantes no curso. 


\title{
A educação superior no Brasil: um breve traçado histórico
}

A educação superior no Brasil começou tardiamente, mesmo se comparado a congêneres latino-americanos (MOROSINI, 2005). Para essa mesma autora, no início do século XIX surgem os primeiros cursos e no século XX a primeira universidade. Lopes (2000) atribui esse surgimento tardio das universidades à resistência forte para criação das mesmas no período da Colônia à República. Tanto Lopes (2000), quanto Morosini (2005), além de outros autores, enfatizam que muitas propostas e projetos (mais de vinte) foram lançados tendo em vista a criação das universidades, mas não tiveram êxito. Essa resistência, sobretudo, proveio da coroa de Portugal, no período Brasil-Colônia e, também, dos próprios brasileiros, os quais pensavam que para fins de educação e realização dos estudos superiores, as elites deveriam ir para a Europa. Lá, de acordo com Lopes (2000, p. 9), “a Universidade de Coimbra era a preferida".

Apesar da resistência da coroa de Portugal, no Brasil, de acordo com Morosini (2005, p. 299), "a criação dos cursos superiores no país ocorreu somente com a vinda da família real portuguesa para o Brasil, em 1808”. O processo de implementação das universidades no Brasil iniciou com muita resistência, seguida de formalizações com legislações que ainda hoje imperam nas nossas universidades. Além desse caráter tardio, tendo a primeira instituição de educação superior sido criada recém em 1808 e as universidades a partir da década de 1930, outra característica importante marca o desenvolvimento da educação superior no nosso país. A autora afirma:

\begin{abstract}
No Brasil, embora tenha havido inúmeras tentativas prévias, até mesmo no século XVI, com o colégio dos jesuítas, com a implantação de cursos superiores no período de D. João VI (1808), ao longo dos períodos imperiais e da República Velha, a universidade é fundada em 1920, através do ato que consubstanciou a Universidade do Rio de Janeiro. Tal ensino foi marcado pela formalização [...], o que é ressaltado pela ocorrência de inúmeras legislações que caracterizam até hoje o ensino superior brasileiro como de magnitude, o maior da América Latina, voltado às elites, com um alto grau de privatização, dependente do governo central, diversificado em instituições públicas e privadas e em cursos de graduação, sequenciais, tecnológicos e de pós-graduação, com um forte sistema nacional de avaliação. (MOROSINI, 2005, p. 296).
\end{abstract}

Essa citação permite visualizar as universidades no Brasil, desde sua idealização, até a sua concepção. Essa característica, de acordo com Durhan (2005, p. 197), “é o desenvolvimento precoce (a partir do final do século XIX) de um poderoso sistema de ensino 
privado paralelo ao ensino público”. A autora afirma que esse setor, já na década de 1960, adquire novas características. Diferentemente de antes, não se trata, simplesmente, da coexistência de sistemas de ordem pública e privada com missões e objetivos semelhantes. "Trata-se de um outro sistema que subverte a concepção dominante de ensino superior centrada na associação entre ensino e pesquisa, na liberdade acadêmica e no interesse público, o qual é constituído por empresas de ensino voltadas para o mercado e o lucro" (DURHAN, 2005, p. 197).

No início da Era Vargas, em 1930, de acordo com Cunha (1980) tinham três universidades em nosso país. Ao final dessa era, 1945, eram cinco. Esse período (+/- 19401960), também, é caracterizado pela modernização da educação superior brasileira pelo modelo norte-americano. Cunha (1988) defende que essa modernização iniciou na segunda metade dos anos 40, ganhou força nos anos 50 e se intensificou nos anos 60, conferindo uma alteração qualitativa nesse processo, as mudanças políticas que resultaram do golpe do Estado de 1964. Depois disso, o autor afirma, que não apenas as agências, como a PONTO IV, USAID, por exemplo, desenvolveram programas maiores e articulados, como o Ministério da Educação não demorou a contratar norte-americanos que auxiliaram na organização do nosso ensino superior, convocando-os a darem assistência ao governo do nosso país em relação ao planejamento das nossas universidades.

Dado curioso, ou não, se nos remetermos àquele contexto, de acordo com Veiga (2007, p. 24), “fazer uma faculdade e se graduar era frequentar um professor da corporação e praticar os atos prescritos para se tornar um mestre (faculdade de artes) ou um doutor (medicina, teologia, direito). [...]". Quando utilizamos o termo "curioso", é pelo motivo de hoje nossas universidades se organizarem de forma bastante distinta, mas, obviamente, o contexto era outro e, de lá para cá, muitas mudanças ocorreram. Segundo a autora, para poder frequentar os mestres das faculdades de artes, antes de ingressar nos estudos superiores, não havia uma exigência legal. No entanto, sem o conhecimento prévio das disciplinas das faculdades de artes, dificilmente se ingressava nos estudos superiores. O conhecimento prévio do latim (que podia ser adquirido em escola ou com mestres particulares) também era necessário para poder ingressar nas faculdades.

A mesma autora ainda destaca que as denominadas universidades da época (séculos XII a XVIII), eram como uma "associação de alunos e mestres para transmissão e aprendizagem de conhecimentos 'desinteressados', [...]” (VEIGA, 2007, p. 17). Além de que as mesmas eram frequentadas predominantemente pelo sexo masculino. Aliás, por tratar dos 
cursos de artes, medicina, teologia e direito, inclui-se aí o de engenharia também, vale destacar que não tinham muitas opções de cursos e, as opções que tinham, de acordo com Cunha (1980), eram voltadas para "utilidades" do período, principalmente, nos casos de guerra.

Pensando na expectativa e na concepção dos graduandos na perspectiva da atuação profissional, este breve traçado histórico nos permitiu analisar como a escolha pelo curso a ser realizado foi se modificando ao longo dos anos. Há tempos, não tínhamos opções de cursos, como vimos, eram oferecidos os mais "básicos", os que pudessem ser úteis para aquele contexto. $\mathrm{O}$ de Pedagogia não estava dentre os primeiros. Aliás, em determinados contextos, para ser professor, bastava ter um pouco mais de instrução que os outros alunos, ser destaque entre os colegas ou mesmo por questões religiosas e culturais, como era frequente notar nas primeiras escolas, provenientes da imigração, que surgiram no nosso país (POSSAMAI, 2005; KREUTZ, 2004).

Atualmente, além de ter um maior rigor na contratação de professor (formação concurso), além de formação em Pedagogia, temos muitas opções de cursos oferecidas, diferentemente da época mencionada anteriormente. Diante dessa ampla variedade surgiu o questionamento sobre a expectativa pela escolha do curso de pedagogia. Onde os graduandos em pedagogia se percebem atuando ou onde têm o interesse de atuar? E teria a instituição um currículo para esse curso que atenda essa demanda de expectativas vivenciada pelos graduandos que optaram por cursar a Pedagogia?

\section{LDB, PNE, DCNS: o que objetivam/defendem?}

A história da educação brasileira é constituída por distintas fases, as quais foram marcadas pela elaboração de leis, pareceres, diretrizes e planos. Nesse texto, iremos nos deter na LDB, (Leis de Diretrizes e Bases 9394), que atualmente é a lei norteadora do ensino brasileiro, no PNE (Plano Nacional de Educação). O mesmo prevê metas a serem cumpridas em período determinado. E, também, nas DCNs (Diretrizes Curriculares Nacionais, Parecer $\mathrm{CNE} / \mathrm{CP} \mathrm{n}^{\mathrm{o}}$ 3/2006), a qual contém especificidades dos cursos de graduação.

De acordo com a LDB, a educação superior tem como uma das finalidades, formar diplomados nas diferentes áreas de conhecimento, aptos para a inserção em setores profissionais e para a participação no desenvolvimento da sociedade brasileira, e colaborar na sua formação contínua. Outra finalidade cabível, de ressaltar aqui, é estimular o conhecimento 
dos problemas do mundo presente para prestar serviços especializados à comunidade em uma relação de reciprocidade. As finalidades expostas na LDB, demonstram a preocupação na formação de profissionais com competência para integrar teoria e prática e atuar na sociedade em que vivem, aperfeiçoando-se permanentemente no âmbito pessoal e profissional.

Ao que diz respeito PNE (2014), as diretrizes que fundamentam a proposta incluem melhorias na qualidade da educação e formação para o trabalho e para a cidadania com ênfase em princípios morais e éticos. Em relação às metas, três estão interligadas com o que nos propomos nesse texto. A meta 12 (MEC ou BRASIL, 2014) tem por objetivo elevar a taxa de matrícula na educação superior, assegurando a qualidade da oferta, entre a população dos 18 aos 24 anos. Elevar a taxa de matrícula é possível, todavia é questionável assegurar a qualidade de oferta, já que concomitante a isso, na maioria das vezes, não aumenta o quadro de profissionais que vão atuar e nem há um aumento no salário daquele profissional que passaria a ter uma turma $50 \%$ maior. Com essa meta nos indagamos se os profissionais que passam a atender $50 \%$ a mais de alunos, provavelmente, sem ter seu salário equiparado a esse aumento, conseguiriam atender ao currículo proposto para o curso em questão (isso se o currículo já satisfizer as demandas daquilo que os graduandos almejam com o curso que estão realizando)?

Sobre melhorias na qualidade da educação superior, a meta 13 ressalta estratégias de aperfeiçoamento dos sistemas de avaliação para auxiliar na qualificação dos cursos de pedagogia e licenciaturas, além do incentivo a pesquisa institucionalizada. Na sequência, em relação à prática do magistério na educação básica, uma das concepções de atuação dos que se graduam em Pedagogia, a meta 15 do PNE (MEC, 2014) contribui objetivando que todos os professores desse nível de ensino possuam formação específica de nível superior (que deve ser obtida em licenciatura na área de conhecimento em que atuam). Essa meta faz com que muitos futuros graduandos, atuais graduandos e/ou graduados vejam na licenciatura a preservação do emprego, sendo essa a "motivação" para cursarem a educação superior.

Das metas já citadas, a meta que viria como auxiliadora nesse processo de atender as demandas dos alunos (do que eles esperam com a realização da graduação) seria a décima terceira, a qual tem a intenção de elevar a qualidade do ensino superior a partir da ampliação de mestres e doutores atuando nessas instituições (esse aumento seria de $75 \%$, sendo 35\% reservado para doutores) (MEC, 2014). Pensamos que essa seria uma meta "auxiliadora" tendo em vista a grande discussão nos programas de pós-graduação sobre a qualidade do ensino e da formação. Talvez com o acréscimo de docentes pós-graduado, poderiam ser 
desenvolvidas mais pesquisas com a temática sobre currículo, e consequentemente estudos específicos que possibilitariam discussões e possíveis mudanças nos currículos dos cursos ofertados na instituição e, também, com relação ao que os futuros profissionais (atuais graduandos) estão buscando.

Ao que diz respeito às DCNs para o curso de Pedagogia, podemos constatar que as mesmas ancoram-se na história do conhecimento em Pedagogia, na história da formação de profissionais e de pesquisadores para a área de Educação. Também busca subsídios no avanço do conhecimento e da tecnologia na área, assim como nas demandas de democratização e de exigências de qualidade de ensino pelos diferentes segmentos da sociedade brasileira.

Analisando o teor da resolução, constatamos que artigo $6^{\circ}$ trata da estrutura do curso de Pedagogia, que é constituído por três parágrafos: I) Núcleo de estudos básicos que possibilitará estudo da literatura e de realidades nacionais; II) Núcleo de aprofundamento e diversificação de estudos voltados às áreas de atuação profissional; III) Núcleo de estudos integradores que proporcionará enriquecimento curricular. No artigo em questão, fica claramente evidenciado o respeito à diversidade nacional e a autonomia das instituições.

As DCNs, por fim, orientam e normatizam princípios e procedimentos a serem observados na organização institucional e curricular. Visam estabelecer bases comuns para que as instituições de ensino possam planejar e avaliar a formação acadêmica e profissional oferecida, acompanhando a trajetória de seus egressos, em padrão de qualidade reconhecido no País.

\section{Percepções sobre os saberes docentes e suas contribuições para o currículo}

O conhecimento é o elemento legitimador da profissão docente, especialmente pelo compromisso em transformar esse conhecimento em aprendizagens relevantes para os alunos. Saber aquilo que se ensina é um dos aspectos primordiais da prática docente, obviamente, aliado ao como ensinar. Não há como dissociar o saber dos professores com as construções sociais, cujos conteúdos, formas e modalidades dependem da história da sociedade e das culturas. Desse modo, é fundamental perceber as evoluções e as mudanças que ocorrem socialmente para dar sentido real tanto aos saberes docentes que dão suporte à prática pedagógica, quanto ao processo de aprendizagem dos alunos, futuros profissionais que atuarão em distintos espaços. 
Diante de tal situação, exige-se cada vez mais que os professores sejam capazes de lidar com os inúmeros desafios suscitados pela massificação do sistema educacional. Vivemos em uma sociedade do conhecimento, em que uma das metas da formação universitária deve ser, a conversão das informações em conhecimentos, e que os mesmos sejam imbuídos de significância para o sujeito aprendente. Para Pozo (2007), a sociedade demanda cada vez mais profissionais capazes de gerir o conhecimento, capazes de aprender, de difundir e produzir de formas diversas o conhecimento acadêmico nas diferentes áreas do saber. Nesse estudo, queremos chamar a atenção, principalmente para importância na área da educação, em especial na formação dos professores, os quais em sua futura profissão irão atuar diretamente com o desenvolvimento humano e os saberes das outras pessoas.

Tardif (2013, p. 11) afirma que "O saber dos professores é o saber deles e está relacionado com a pessoa e a identidade deles, com a sua experiência de vida e com a sua história profissional, com as suas relações com os alunos em sala de aula e com os outros atores escolares na escola, etc". O saber docente, portanto, não é uma substância ou um conteúdo fechado em si mesmo, se manifesta pelas relações entre professores e alunos. Em outras palavras, Tardif (2013) afirma que o saber dos professores não é um conjunto de conteúdos cognitivos, mas um processo em construção ao longo de uma carreira profissional na qual o professor aprende progressivamente a lidar com seu ambiente de trabalho inserindose nele.

É notória a existência de contrariedades entre a prática do professor e o tipo de formação que a ele é oferecida. "[...] é estranho que a formação dos professores tenha sido e ainda seja bastante dominada por conteúdos e lógicas disciplinares, e não por profissionais" (TARDIF, 2013, p. 240). O autor lamenta ainda que na formação de professores ensinam-se teorias, que na maioria das vezes não tem relação alguma com as realidades cotidianas do ofício do professor e funciona por disciplinas e de maneira fragmentada.

O fundamental nesse caso, não é esvaziar a lógica disciplinar dos programas de formação para o ensino, mas abrir e ampliar o espaço para uma lógica de formação profissional que reconheça os alunos como sujeitos do conhecimento e participantes ativos no processo de ensino e de aprendizagem, com enfoque reflexivo acerca da prática docente. Nesse sentido, é essencial destacar que as tarefas dos docentes consistem em desenvolver não uma única capacidade de pensar, mas muitas capacidades particulares de pensar em campos diferentes, não em reforçar a nossa capacidade geral de prestar atenção, mas em desenvolver diferentes maneiras de concentrar a atenção sobre diferentes conteúdos. 
Compactuamos com Pozo (2007), quando defende que é necessário enfatizar a flexibilidade, fiabilidade e caráter construtivo no conhecimento que se ensina na universidade. O currículo, não pode abranger fundamentos com fim em si mesmo, nem mesmo reduzir-se a acumulação de saberes desconectados entre si. Ao contrário, o currículo tem fundamental importância no papel de articulador e integrador de saberes, que dialogam e permeiam teoria e prática.

O que se estuda dentro do sistema educativo, está organizado com base em um currículo ordenados da prática. No sentido etimológico, a palavra currículo advém do latim, curriculum, alude tanto a uma corrida, como àquilo com o qual se faz a corrida. (CASTELLO; MÁRSICO, 2007). No âmbito educativo, o currículo trata do trajeto educativo, às instâncias que devem ser percorridas para determinada matéria ou curso. O currículo revela escolhas, resultantes de decisões baseadas em aspectos culturais, históricos, sociais, políticos e pedagógicos.

"Quais os princípios básicos do currículo?" O que os estudantes têm direito de aprender? Assim questiona Young (2013, p.11) em um de seus escritos sobre a superação da crise em estudos curriculares. Sem dúvida, não existem respostas fixa para tais questionamentos, tendo em vista as contínuas mudanças e avanços tecnológicos que fazem parte da evolução humana, porém, de acordo com Young, é necessário aos educadores manter viva a história, repassando aos estudantes, as descobertas de gerações passadas.

Por outro lado, o propósito do currículo é preparar as pessoas para que possam construir e reconstruir conhecimentos. Ou seja, necessitamos criar novos conhecimentos que engrandecem o currículo dos cursos, e aproximam das realidades atuais, mas, não podemos esquecer a gênese histórica dos conhecimentos que constituíram a base para chegar até onde estamos. Esse processo pode promover práticas que não repitam equívocos anteriores, além de subsidiar no desenvolvimento de currículos inovadores que respeitem a diversidade e minimize as desigualdades. Como afirma Young (2013), um currículo que maximize as chances de que todos os alunos terão acesso ao melhor conhecimento.

Para tanto, temos que pensar em um currículo que, de maneira flexível e inovadora, busque o desenvolvimento pleno dos sujeitos aprendentes. Um currículo que, por um lado, enfatize o "conhecimento poderoso", o desenvolvimento intelectual (Young, 2011), ao mesmo tempo em que, envolva a perspectiva do currículo como produção cultural, defendida por Fabris (2007). O currículo para a autora é produzido na cultura e, por sua vez, produz sentidos que colocados em circulação, constituem os sujeitos escolares. 
É por isso que o currículo precisa ser elaborado pelas pessoas que estão envolvidas no processo de ensino e de aprendizagem. Se a construção do currículo for hegemonia da gestão ou assessorias, a reponsabilidade dos professores e dos alunos será somente dar contas dos conteúdos expostos no currículo. Com isso, Hargreaves (2004) afirma que ao invés de estimular a criatividade e a inventividade, os sistemas educacionais se tornam cada vez mais impositivos, priorizando a uniformidade curricular.

O currículo precisa envolver o cultivo de capacidades que preconizem o desenvolvimento da aprendizagem cognitiva profunda, o incentivo para a criatividade e para a inventividade entre os estudantes, além da utilização da pesquisa, do trabalho em redes e equipes (HARGREAVES, 2004). Deve também buscar a aprendizagem profissional contínua por parte dos professores e a promoção da solução de problemas, a disposição de correr riscos, a confiança nos processos cooperativos e a capacidade de lidar com a mudança como possibilidade de melhorias para a educação e a sociedade.

Em consonância com essas ideias, Masetto (2011) concebe o currículo na educação superior como um conjunto de conhecimentos, saberes, competências, habilidades, experiências, vivências e valores organizados de maneira integrada, tendo como princípio a formação de profissionais preparados para uma sociedade contextualizada num determinado tempo e espaço histórico, político, econômico e social. A elaboração do currículo supõe, por parte dos professores e especialistas, diálogos e interações que perpassem os espaços universitários e busquem conhecimentos externos, que dizem respeito às transformações sociais e às necessidades das pessoas e sobre as novas exigências das carreiras profissionais.

Gatti, Barreto e André (2011) ao desenvolver pesquisas sobre políticas docentes no Brasil, afirmam que a da formação inicial de professores tem importância ímpar, uma vez que desenvolve o alicerce sobre o qual os profissionais irão exercer a atividade educativa em diferentes ambientes. Percebem, no entanto, lacunas eminentes da formação inicial que implicam na desconexão entre as necessidades práticas reais e os componentes teóricos do currículo dos cursos. Para as autoras, nas instituições de ensino superior brasileiras há predomínio de formação acadêmica, mais abstrata, de caráter excessivamente genérico. Não significa que esse tipo de formação não seja necessário, mas insuficiente para a formação de docentes na sua integralidade.

A formação inicial dos profissionais da Pedagogia requer constante mobilização dos saberes adquiridos em situações reais do cotidiano. É essencial que o próprio sujeito, o estudante de Pedagogia, se coloque no centro de seu processo de formação e desenvolva 
condições de confrontar-se com problemas complexos e variados, “[...] estando capacitado (a) para construir soluções em sua ação, mobilizando seus recursos cognitivos e afetivos." (GATTI; BARRETO; ANDRÉ, 2011, p. 93).

Bolzan (2008) discorre sobre tensões existentes na pedagogia universitária e defende a inovação curricular por meio do protagonismo pedagógico, gerado a partir de redes de compartilhamentos. A aprendizagem desse processo se dá mediante a multiplicidade de ideias e posições, as quais podem ser questionadas e contraditas na busca de sentidos e significados capazes de romper com modelos de ensino engessados no ambiente universitário. “[...] precisam-se encontrar formas genuínas de construção de saberes, dinamizando as inovações, difundindo experiências e considerando o contexto global e local, no qual o processo pedagógico se institui." (BOLZAN, 2008, p. 117-118).

A universidade precisa priorizar um currículo integrado, que possibilite aprendizagens significativas e auxilie os estudantes a adquirir estratégias e capacidades que permitam transformar e reconstruir as informações que recebem com ética, autonomia e criticidade. Além do mais, que esse currículo possa ir ao encontro das necessidades sociais, e cumprir com seu papel na construção do conhecimento. Nesse sentido, a responsabilidade dos professores está na própria prática pedagógica, nas escolhas e decisões tomadas, a partir dos saberes, experiências e postura metodológica assumidos.

\section{Percurso metodológico}

O presente estudo trata de um recorte de uma pesquisa em andamento em um grupo de pesquisa da qual as autoras fazem parte. Os dados já foram coletados através de questionários aplicados em distintos cursos da graduação, porém para essa pesquisa utilizou-se apenas os aplicados no curso de Pedagogia, que totalizaram 52 questionários. O referido questionário é composto por diversas questões (abertas e fechadas), no entanto, para esse estudo selecionamos apenas a terceira questão. A mesma indaga sobre o conhecimento das possibilidades de atuação profissional do graduado nessa área.

Além disso, realizamos uma análise criteriosa do currículo do curso de Pedagogia da Instituição, comparando com as DCNs e, ao mesmo tempo, verificando se o currículo atende as expectativas dos discentes em relação à área de atuação profissional. Vale ressaltar que o currículo da referida instituição encontra-se em transição, por isso, mesmo que ambos estejam ativos, pensamos na pertinência de trabalhar com o currículo reestruturado. Para tanto, nos 
debruçamos na abordagem mista (quali-quantitativa), para a análise dos dados aqui apresentados, guiando-nos, principalmente, na Análise Textual Discursiva (MORAES; GALIAZZI, 2013), para a análise dos dados.

Esse método de análise utiliza as categorias como forma de focalizar o todo por meio das partes. É um processo auto-organizado de produção de novas compreensões em relação aos fenômenos que examina. Segundo os autores, quando se conhece a priori os temas da análise, separam-se as unidades de sentido de acordo com os temas. Essa análise consiste em desmontar os textos, estabelecer relações, captar o novo emergente, unitarizar, categorizar e, por fim, passar para a etapa de impregnação/compreensão aprofundada do texto em análise, ou melhor, das entrevistas, como é o caso do presente projeto.

A escolha da Análise Textual Discursiva para a análise das entrevistas da presente pesquisa se dá por sua pertinência e completude. Moraes e Galiazzi (2013) comparando a Análise de Conteúdo (AC), a Análise de Discurso (AD) e a Análise Textual Discursiva (ATD), afirmando que as três metodologias se encontram num mesmo domínio, o da análise textual, mas que, ainda, assim, apresentam similaridades não relacionadas às suas qualidades, mas ao grau de profundidade. Utilizando a metamorfose do rio, os autores defendem que a primeira (AC) assemelha-se a um percurso de rio, que segue a correnteza; a segunda (AD) age como se fosse navegar contra a correnteza; e, por fim, a terceira (ATD), por nós acolhida, que não vai nem contra e nem a favor da correnteza, mas prefere explorar a sua profundidade.

A ATD “corresponde a uma metodologia de análise de dados e informações de natureza qualitativa com a finalidade de produzir novas compreensões sobre os fenômenos e os discursos" (MORAES; GALIAZZI, 2013, p. 7). Durante todos os processos, os autores enfatizam a necessidade de envolvimento intenso e rigoroso do pesquisador no processo de análise e reconstrução. Ao longo do livro a metodologia é apresentada como processo autoorganizado e emergente, que se fundamenta no poder criativo de sistemas complexos e caóticos.

\section{Análise dos dados}

De acordo com a pergunta: "Você sabe em quais atividades um profissional que possui a graduação que você está cursando pode atuar? Cite-as.", obtivemos respostas nos mais diversos segmentos, que categorizamos em: 


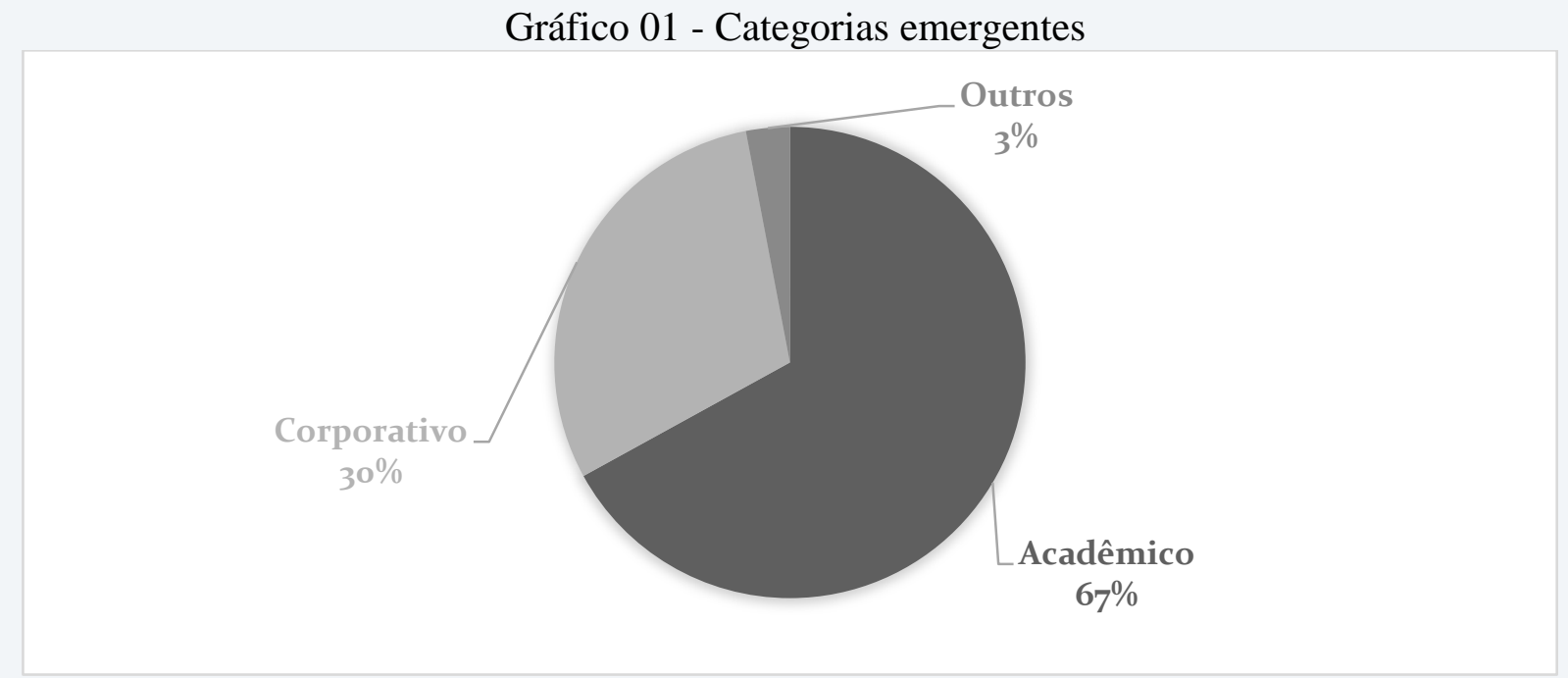

Fonte: as próprias autoras.

A categoria "Acadêmico" refere-se às atividades envolvendo instituições e ambientes escolares em diferentes níveis de ensino. Inserido na categoria "Acadêmico", encontramos como possibilidades de atuação, pelo conhecimento dos discentes: professor, Educação de Jovens e Adultos, coordenador escolar, educador social, direção escolar, supervisão, orientador escolar, centros educativos, planejamento escolar, consultoria para escola, auxiliar e inclusão. Para exemplificar e justificar tal categoria, extraímos alguns argumentos dos estudantes:

Certamente não sei todas as atividades que se poderia atuar, até porque cada vez surgem novos campos de atuação para pedagogos. Algumas atividades são como: professor em anos iniciais, educação infantil, EJA, como coordenador pedagógico, auxiliar de coordenação. (E1)

Em escolas com Educação Infantil e Séries Iniciais, dentro da sala. Como coordenadora e diretora de escola. (E2)

Ao que diz respeito a categoria "Corporativo", observamos respostas que incluem: empresas, hospitais, ONGS, clínicas e instituições. Denominamos de "corporativo" tal categoria, por estar ligada ao conceito de afinidades profissionais que geralmente se organizam por regulamentos ou estatutos. Já na categoria "Outros", encontramos como respostas: espaços não formais e biblioteca. Os estudantes incialmente citam atividades de cunho acadêmico, no entanto, justificam que atualmente há distintas possibilidades de atuar em outras áreas: 
Pode atuar nas mais diversas áreas que envolvem contexto educativo. Pode atuarem escolas enquanto professor, mas também em muitos outros contextos enquanto pedagogo, como empresas, ONGs, hospitais, centros educativos diversos. " (E3)

Hoje o pedagogo pode se encaixar em várias áreas: técnico em educação hospitalar, docentes de anos iniciais, infantil e EJA. Docentes em espaços não formais, entre outros. Educador Social na área de assistência. Escolas empresas e na área de recursos humanos e treinamentos. (E4)

Confrontando as expectativas citadas pelos discentes com o currículo do curso em questão, percebemos consideráveis aproximações entre as expectativas discentes e as disciplinas que o curso oferece. Salientamos que na categoria "Acadêmico", todas as opções encontram-se, de alguma forma, atendidas no currículo. Nessa categoria, vale destacar que direção escolar, supervisão, orientador escolar e planejamento escolar, estão incluídas na disciplina de Gestão de Espaço Educativo e Estágios Supervisionados.

Diferentemente, na categoria "Corporativo", as expectativas mencionadas não estão nítidas na nomenclatura das disciplinas, exceto em nossa percepção na disciplina Educação em Espaços Não Formais. Inclusive, essa disciplina se adapta a uma das expectativas mencionadas na categoria "Outros". A outra expectativa (biblioteca) referente a mesma categoria, não consta no currículo, mas também não vimos sua obrigatoriedade, já que existem cursos específicos para a área.

Quanto a análise comparativa do currículo da instituição com as DCNs para o curso de Pedagogia, no qual percebemos a consonância de todas as aptidões previstas. Ou seja, a estrutura curricular da instituição, atende as demandas dos DCNs, não se apresentando de forma linear e estanque. Todavia, não podemos deixar de citar os dizeres de uma estudante, sobre a preocupação de uma estudante sobre o reducionismo curricular:

Fico preocupada quando vejo mudanças no currículo que parecem afunilar as possibilidades de colocações futuras. Pretendo encontrar na graduação, uma formação que contemple a educação como um processo que envolva todas as pessoas e não somente crianças. (E5)

Apesar dos resultados encontrados apontarem para o atendimento das exigências da legislação, há uma preocupação por parte dos estudantes em dar conta das demandas sociais em diferentes contextos e faixas-etária, bem como o envolvimento com as próprias preferências de atuação dos estudantes. Esses fatores, nos levam a refletir e indagar: Para que e para quem é o currículo? Quem faz e quem deveria participar da construção do currículo? 


\section{Considerações}

Com base nas análises e nas reflexões apontadas no texto, concluímos que o currículo do curso na graduação é de extrema importância para a formação profissional docente, já que ampara todo o andamento e organização dos processos de ensino e de aprendizagem. Por isso, a relevância de que o currículo seja flexível e democrático, possibilitando que todos os envolvidos tenham participação efetiva na avaliação e reestruturação constante. Esse movimento possibilitaria a ligação da universidade com a sociedade, bem como, o atendimento das demandas dos alunos para a atuação profissional.

Quando trazemos a questão da flexibilidade, fazemos isso, tendo conhecimento das exigências da legislação e de sua importância, mas que, no entanto, de acordo com o contexto local em que a instituição esteja inserida, há a necessidade de flexibilização, visando adequação com o público para o qual está regido. Além do mais, essa questão também deve estar voltada para as necessidades contemporâneas, visando a adequação do currículo para que o professor esteja preparado para lidar com tais necessidades e demandas.

Especificamente para o contexto local-temporal que analisamos, não podemos afirmar que o currículo da instituição que analisamos tenha sido construído coletivamente, no entanto, foi possível observar que ele atende, em grande parte, as expectativas dos seus discentes. Essa observação foi possível, em virtude do que está posto no currículo e nas falas/respostas dos discentes entrevistados. Além disso, percebemos que a construção do mesmo segue os parâmetros do sistema educacional nacional que prevê o diálogo com as necessidades sociais.

Como mostramos anteriormente, a maioria dos entrevistados percebe sua capacitação voltada para a categoria "acadêmico", por esse motivo, uma das sugestões das autoras é que o currículo pudesse atender de forma mais notória, a atuação nos outros segmentos, instigando e atraindo mais discentes para a área da educação. Também, seria interessante a inserção no currículo de práticas pedagógicas e/ou estágios nesses outros segmentos, tornando-os conhecidos para todos os discentes dessa área. Como futuras ações, almejamos desenvolver um estudo qualitativo com os sujeitos, instigando-os a pensarem sobre o currículo do curso que estão realizando e a efetividade de outras áreas de atuação.

Por fim, ainda no viés da nossa inquietação, das fragilidades encontradas e de um futuro foco para novas investigações, cabe destacar que nossa preocupação com o tema em pesquisa deve-se, a incansável busca por transformações que possam incidir na qualidade da 
formação e saberes dos docentes. Para além de pragmáticas conclusões, os achados desse estudo, instituíram outas indagações: que currículo precisamos? Que currículo desejamos? Como pensar em uma base curricular comum que tenha como foco as necessidades sociais, mas que ao mesmo tempo atenda as individualidades de cada estudante? De que forma desenvolver verdadeiramente o protagonismo e a autoria no ambiente da sala de aula universitária?

\section{Referências}

BOLZAN, Doris Pires Vargas. Pedagogia universitária e processos formativos: a construção do conhecimento pedagógico compartilhado. In: XIV Encontro Nacional de Didática e Práticas de Ensino - ENDIPE - Trajetórias e processos de ensinar e aprender: didática e formação de professores. Anais... Porto Alegre, 2008. Disponível em: <http://w3.ufsm.br/gtforma/estagio1/6bd9982dc814272dbbedbdac75bd96ed.pdf>. Último acesso em: 08 jun. 2016.

BRASIL. [Plano Nacional de Educação (PNE)]. Plano Nacional de Educação 2014-2024 [recurso eletrônico]: Lei no 13.005, de 25 de junho de 2014, que aprova o Plano Nacional de Educação (PNE) e dá outras providências. - Brasília: Câmara dos Deputados, Edições Câmara, 2014. Disponível em:

http://www.observatoriodopne.org.br/uploads/reference/file/439/documento-referencia.pdf. Último acesso: 28 abr. 2016.

BRASIL. LDB - Lei de Diretrizes e Bases da Educação Nacional: Lei nº 9.394, de 20 de dezembro de 1996, que estabelece as diretrizes e bases da educação nacional [recurso eletrônico]. Brasília: Câmara dos Deputados, Edições Câmara, 2013.

BRASIL. MEC. CNE. Parecer CNE/CP No: 5/2005. Diretrizes Curriculares Nacionais para o curso de Pedagogia. Diário Oficial da União, 15 de maio de 2006. Disponível em: http://portal.mec.gov.br/cne/arquivos/pdf/rcp01_06.pdf. Último acesso: 01 mai. 2016.

CASTELLO, Luis A; MÁRSICO, Claudia T. Oculto nas palavras: dicionário etimológico para ensinar e aprender. Belo Horizonte: Autêntica, 2007.

CUNHA, Luiz Antônio. A universidade reformada: o golpe de 1964 e a modernização do ensino superior. Rio de Janeiro: Francisco Alves, 1988.

CUNHA, Luiz Antônio. A universidade temporã: o ensino superior da Colônia à Era de Vargas. Rio de Janeiro: Civilização Brasileira, 1980.

DURHAN, Eunice R. Educação superior, pública e privada (1808-2000). In:

SCHWARTZMAN, Simon; BROCK, Colin (Orgs.). Os desafios da educação no Brasil. Tradução de Ricardo Silveira. Rio de Janeiro: Nova Fronteira, 2005. p. 197-240.

ENGERS, Maria Emília Amaral. Pedagogia Universitária e aprendizagem. Porto Alegre: EDIPUCRS, 2007. 
FABRIS, Elín T. Henn. A escola contemporânea: um espaço de convivência? In: $30^{\circ}$ Reunião Associação Nacional de Pós-graduação e Pesquisa Em Educação - ANPEd. Anais...

Caxambu, 2007. Disponível em: 30reuniao.anped.org.br/trabalhos/trabalho_gt13.htm. Último acesso em: 20 maio 2016.

GATTI, Bernardete Angelina; BARRETO, Elba Siqueira de Sá; ANDRÉ, Marli Eliza Dalmazo de Afonso. Políticas docentes no Brasil: um estado da arte. Brasília: UNESCO, 2011.

HARGREAVES, Andy. O ensino na sociedade do conhecimento: a educação na era da insegurança. Porto Alegre: Artmed, 2004.

KREUTZ, Lúcio. O professor paroquial: magistério e imigração alemã. Pelotas: Seiva, 2004.

LOPES, José Leite. Prefácio- A Universidade no Brasil: um histórico e um alerta. In: FÁVERO, Maria de Lourdes de Albuquerque. Universidade do Brasil: das origens à construção. Rio de Janeiro: UFRJ/Inep, 2000. p. 9-12.

MASETTO, Marcos Tarciso. Inovação curricular no ensino superior. Revista e-curriculum, São Paulo, v. 7, n. 2, ago. 2011. Disponível em: http://revistas.pucsp.br/index.php/curriculum. Último acesso em: 03 mai. 2016.

MORAES, Roque; GALIAZZI, Maria do Carmo. Análise textual discursiva. Coleção Educação em Ciências. 2. ed. Ijuí: UNIJUÍ, 2013.

MOROSINI, Marilia. O ensino superior no Brasil. In: STEPHANOU, Maria; BASTOS, Maria Helena Camara (Orgs.). Histórias e memórias da educação no Brasil. Volume III: século XX. Petrópolis: Vozes, 2005. p. 296-323.

POSSAMAI, Paulo César. "Dall'Itália siamo partiti": a questão da identidade entre os imigrantes italianos e seus descendentes no Rio Grande do Sul (1875-1945). Passo Fundo: UPF, 2005.

POZO, Juan Ignácio. Aprender en la sociedad del conocimiento. In: ENGERS, Maria Emília Amaral. Pedagogia Universitária e aprendizagem. Porto Alegre: EDIPUCRS, 2007. p. 39-56.

TARDIF, Maurice. Saberes docentes e formação profissional. Petrópolis: Vozes, 2013.

VEIGA. Cynthia Greive. História da educação. São Paulo: Ática, 2007.

YOUNG, Michael. A superação da crise em estudos curriculares: uma abordagem baseada no conhecimento. In: FAVACHO, André M. P.; PACHECO, José Augusto; SALES, Shirlei R. (Org.). Currículo: conhecimento e avaliação divergências e tensões. Curitiba, PR: CRV, 2013. p. 11-32.

YOUNG, Michael F. D. O futuro da educação em uma sociedade do conhecimento: o argumento radical em defesa de um currículo centrado em disciplinas. Tradução de Laura Beatriz Áreas Coimbra. Revista Brasileira de Educação, v. 16, n. 48, p. 609-623, set./dez. 2011. 


\section{$\underline{\text { SOBRE AS AUTORAS }}$}

\section{Carla Spagnolo}

Doutora em Educação pela Pontifícia Universidade Católica do Rio Grande do Sul (PUCRS). Membro do Grupo de Pesquisa Processos Motivacionais em Contextos Educacionais (PROMOT). Atualmente possui bolsa de pesquisa em Educação Superior e Metodologias Ativas pelo Programa Nacional de Pós-doutorado PNPD/CAPES/MEC no Programa de PósGraduação em Educação/PUCRS, vinculada ao Centro de Estudos em Educação Superior (CEES). E-mail: carla.spagnolo@ pucrs.br

\section{Jordana Wruck Timm}

Doutora em Educação pela Pontifícia Universidade Católica do Rio Grande do Sul (PUCRS). Membro do Grupo de Pesquisa Processos Motivacionais em Contextos Educacionais (PROMOT). Atualmente possui bolsa de pesquisa pelo Programa Nacional de Pós-Doutorado PNPD/CAPES/MEC e é professora colaboradora no Programa de Pós-Graduação em Educação da Universidade Regional Integrada do Alto Uruguai e das Missões (URI), campus de Frederico Westphalen. E-mail: jordana.timm@acad.pucrs.br

\section{Bettina Steren dos Santos}

Doutora em Psicologia Evolutiva e da Educação pela Universidad de Barcelona (UB), na Espanha. Pós-doutorado no College of Education, The Univesity of Texas at Austin (UTAustin), nos Estados Unidos. Professora titular do Programa de Pós-Graduação em Educação da Pontifícia Universidade Católica do Rio Grande do Sul (PUCRS). Membro do Grupo de Pesquisa Processos Motivacionais em Contextos Educacionais (PROMOT). Bolsista de Produtividade em Pesquisa. E-mail: bettina@pucrs.br 